\title{
Ronald Chilcote, The Portuguese Revolution: State and Class in the Transition to Democracy
}

Jawdat Abu-El-Haj

\section{(2) OpenEdition}

\section{Journals}

Edição electrónica

URL: http://journals.openedition.org/rccs/4447

DOI: $10.4000 /$ rccs. 4447

ISSN: 2182-7435

Editora

Centro de Estudos Sociais da Universidade de Coimbra

\section{Edição impressa}

Data de publição: 1 dezembro 2011

Paginação: 164-166

ISSN: 0254-1106

\section{Refêrencia eletrónica}

Jawdat Abu-El-Haj, « Ronald Chilcote, The Portuguese Revolution: State and Class in the Transition to Democracy ", Revista Crítica de Ciências Sociais [Online], 95 | 2011, posto online no dia 01 dezembro 2012, consultado o 21 setembro 2020. URL : http://journals.openedition.org/rccs/4447 ; DOI : https:// doi.org/10.4000/rccs.4447 


\section{Recensões}

\section{Colin Crouch (2011), The Strange Non-Death of Neoliberalism. Cambridge: Polity Press, 224 pp.}

O que não aconteceu, mas, em certas circunstâncias, podia ter acontecido, pode ser um objeto bem profícuo de investigação no campo da economia política enquanto teoria social crítica. Lembremos os estudos de Hyman Minsky nos anos setenta e oitenta, hoje justamente considerado um dos mais prescientes analistas da instabilidade financeira do capitalismo. A sua investigação procurou compreender o que não aconteceu no pós-guerra: uma depressão como a dos anos trinta. Minsky destacou o papel dos governos e bancos centrais, que foram capazes de mobilizar amplos recursos na estabilização macroeconómica e no controlo público do setor financeiro. O último livro de Colin Crouch procura, nesta senda, deslindar a mais paradoxal questão da economia política no novo contexto depressivo: como é que um feixe de ideias que inspirou as mais profundas transformações institucionais das últimas décadas - o neoliberalismo - pôde gerar resultados tão desastrosos, à vista de todos na crise financeira de 2008-2009, e ainda assim exibir uma tão grande e surpreendente resiliência política. Exemplo desta hegemonia são as políticas de austeridade, de privatização e de desregulamentação em curso, em especial no eixo Atlântico Norte, que tem prioridade na análise.

O objeto deste livro é então algo que foi anunciado, por exemplo, quando se afirmou que o colapso do setor financeiro seria o que a queda do Muro de Berlim foi para o comunismo, mas que estranhamente não aconteceu - a desaparição do neoliberalismo. O seu autor, Colin Crouch, tornou-se uma das principais referências do campo transdisciplinar de estudos económicos designado por modelos ou variedades de capitalismo. Trata-se de um campo de análise comparada onde se reconhece que as instituições fundamentais das economias capitalistas - dos mercados às empresas, passando pelo Estado ou pelas formas que a vida associativa assume - exibem uma assinalável plasticidade e variabilidade histórico-espacial e combinam-se de formas mais ou menos coerentes e sustentáveis, sendo importante considerar as origens e os efeitos de constelações institucionais que desafiam as teses demasiado apressadas sobre um "mundo plano" em globalista convergência.

Este ponto de partida científico, com as suas virtudes e os seus limites, manifesta-se por vezes no livro e explica a atenção dada precisamente ao insuperável triângulo Estados-mercados-empresas, às confrontações e acomodações institucionais que ocorrem no seu seio, e ao papel que o neoliberalismo teve na sua configuração nas últimas décadas. A tese central resume-se facilmente neste contexto: embora ideologicamente comprometido com a expansão das forças do mercado concorrencial, supostamente à custa do papel dos Estados e do poder das empresas, a prática política neoliberal, assente na privatização, liberalização e desregulamentação, mas também em formas híbridas de submissão dos serviços e investimentos públicos a uma lógica de controlo empresarial, acabou por contribuir para o reforço do poder das grandes empresas e grupos económicos que, em plena crise, souberam, pelo menos até agora, manter o status quo. Trata-se de ir 
para lá da repetida oposição entre Estados e mercados, para destacar o papel das empresas enquanto atores políticos de monta, com capacidade para moldar as políticas públicas, sobretudo as que estão associadas à estruturação e abertura de novos mercados, quasi-mercados ou mesmo monopólios. Bom exemplo disso são as parcerias público-privadas, no quadro da colonização neoliberal de uma social-democracia apostada em manter residualmente alguns valores de inclusão num quadro de restauração do poder capitalista. Sendo precisamente expressões organizacionais do poder do capital, é inevitável, num contexto de enfraquecimento dos contrapoderes sociais e de domínio de ficções ideológicas sobre o "mercado livre", que o seu poder económico se traduza em poder político, expressando assim a necessária, embora variada, imbricação entre economia e política. Crouch não deixa de chamar a atenção para este facto. Por exemplo, num dos mais úteis momentos do livro, Crouch deslinda a debatida questão de saber se a (re)conquistada capacidade das grandes empresas em operar à escala global estaria a operar uma corrida para cima ou para baixo em matéria de normas sociais, laborais ou ambientais, argumentando que o enfoque deve estar a montante, na capacidade das grandes empresas para definir grande parte das regras das corridas entre os Estados, assim contribuindo para nos fazer entrar cada vez mais numa trajetória "pós-democrática".

O livro vale então pelos capítulos quatro e cinco - "empresas privadas e negócios públicos" e "keynesianismo privatizado". Focando-se sobretudo no Reino Unido, Crouch identifica bem as perversidades da chamada nova gestão pública e como o seu esforço para introduzir mecanismos mercantis na esfera pública se saldou por uma captura de bens e serviços por grandes empresas. Neste contexto, é identificado um dos dilemas fundamentais da estratégia neoliberal como engenharia política: ao querer separar a política da economia, reduzindo o espaço para a intervenção pública, o neoliberalismo acaba por multiplicar o campo para a promiscuidade entre público e privado, erodindo no processo o etos e as instituições que protegiam a integridade de muitas áreas da provisão pública. Um outro dilema, desta vez macroeconómico, é também bem escrutinado. Fortemente anti-keynesiano, o neoliberalismo atacou com sucesso as forças sociais e as instituições - dos sindicatos à contratação coletiva, passando pelos controlos de capitais e outras medidas da chamada "repressão financeira" - que sustentavam o consenso keynesiano. Uma das consequências do novo regime marcado pela ascensão da finança de mercado e por uma maior pressão para a criação de valor para o acionista foi o enfraquecimento sistémico da procura salarial. O "keynesianismo privatizado" corresponde a um esforço, particularmente visível no capitalismo anglo-saxónico, para sustentar a procura de assalariados vulneráveis através da expansão do crédito, combatendo assim as tendências estagnacionistas. A outra face desta moeda foi a oportunidade oferecida aos mais ricos para a canalização dos seus rendimentos crescentes para a especulação oleada pela inovação financeira. A crise financeira revelou os limites deste modelo, ao mesmo tempo que mostrou como as poderosas instituições financeiras aprenderam a socializar as perdas e a privatizar os ganhos.

Aqui chegados, coloca-se a pergunta: quais são as alternativas a este estado de coisas? E é aqui que o livro mais desilude, já que Crouch não crê ser possível ou desejável, em virtude dos elevados custos económicos que supostamente teria, reverter a marcha política da globalização económica, que tanto poder confere ao grande 
capital para dividir e reinar sobre o trabalho. Em vez de se engajar seriamente com a literatura sobre a desglobalização, com a sua análise dos custos socioeconómicos e políticos da globalização neoliberal e com as suas propostas, Crouch prefere incompreensivelmente associá-la a nacionalismos declarados retrógrados. Em vez disso, o leitor é confrontado com dois penosos capítulos finais sobre a possibilidade de usar a responsabilidade social das empresas como pretexto para fazer reentrar os "valores" na sua ação, a partir de uma análise pluralista de uma nebulosa sociedade civil cosmopolita que se conformou a viver com a grande empresa e, no fundo, com os seus momentos pós-democráticos, tendo de aprender a polir as suas arestas. Para além de ser surpreendentemente esvaziada de relações de poder, de classes sociais, suas frações, conflitos e alianças, ao contrário do que acontece em muita da literatura existente - por exemplo, Bastiaan van Apeldoorn e Henk Overbeek (2012), "Introduction: The Life Course of the Neoliberal Project and the Global Crisis", in Bastiaan van Apelddorn e Henk Overbeek (orgs.), Neoliberalism in Crisis. London: Palgrave, 1-20 -, esta parte da análise não fornece pistas propositivas para este projeto ou uma defesa sustentada dos valores que teríamos boas razões para querer injetar nas empresas.

A jusante desta leitura conformista, o livro revela problemas cruciais de análise relacionados com a natureza dos mercados e do coletivo neoliberal que vale a pena mencionar. Surpreendentemente, para um autor que converge com a tradição da economia política institucionalista, Crouch adota o quadro de análise dos mercados da teoria económica convencional. Neste, os mercados "livres" e concorrenciais são as instituições que tendem a emergir por defeito, justificando-se a intervenção do Estado para corrigir as falhas que os afastam do funcionamento idealizado pela teoria - das externalidades aos bens públicos, passando pela informação assimétrica ou pela concorrência imperfeita. Neste quadro, os neoliberais tendem a subestimar essas falhas, destacando, pelo contrário, as falhas do governo, as falhas da regulação. O problema é que Crouch acaba por cair na armadilha neoliberal de ver o idealizado mercado concorrencial como princípio económico regulador normativo, usando o termo "mercado livre” para o descrever. Isto quando se sabe que se os mercados, enquanto espaços de transação de mercadorias cujo valor se cristaliza num preço, podem ter várias reconfigurações, diferentes distribuições de direitos e obrigações, diferentes liberdades e exposições a essas liberdades para os diferentes agentes que neles interagem, mas são sempre espaços de poder que ameaçam o laço social. Isto quando se sabe também, e Crouch não desenvolve esta linha, que os mercados pressupõem sempre uma intervenção forte por parte do poder político. De resto, Crouch não sublinha, ao contrário do que acontece com análises historiográficas mais rigorosas - Philip Mirowski e Dietre Plehwe (2009), The Road from Mont Pelerin: The Making of the Neoliberal Thought Collective. Cambridge, MA: Harvard University Press -, como o neoliberalismo é um coletivo intelectual que, longe de ser homogéneo, é, no entanto, atravessado pela mesma suspeição não tanto em relação a um Estado absolutamente necessário para esta engenharia política, mas sim em relação à prática democrática soberana e à ação coletiva de classes subalternas preocupadas com o pleno emprego ou com a desmercadorização de bens sociais. Crouch dissocia o ordoliberalismo alemão, e a sua economia social de mercado, do neoliberalismo. Trata-se de um erro que a história das ideias corrige, já que o próprio termo neoliberalismo foi cunhado por Alexander Rostow, um ordoliberal 
alemão, e que a expressão "economia social de mercado" reflete a convicção de que a expansão dos mercados, garantida, como não podia deixar de ser, por políticas conformes com este objetivo, gera as melhores consequências económicas e morais. O "neoliberalismo disciplinar" (Stephen Gill [2002], "Constitutionalising Capital: EMU and Disciplinary Neo-Liberalism”, in Andreas Biller e Adam Morton (orgs.), Social Forces in the Making of the New Europe. London: Palgrave, 47-69) da União Europeia, aliás um arranjo decisivo, mas ignorado por Crouch, para explicar a sua resiliência no Continente, deve muito ao ordoliberalismo alemão.

Em suma, este livro indica-nos como uma boa questão de investigação pode não ser respondida de forma inteiramente satisfatória. De qualquer forma, não deixa de ser uma adição relevante na cada vez mais vasta estante sobre uma doutrina que até há pouco tempo ainda era considerada como um slogan sem dignidade intelectual.

João Rodrigues

\section{Debra Satz (2010), Why Some Things Should Not Be for Sale? The Moral Limits of Markets. Oxford: Oxford University Press, 252 pp.}

O atual contexto de crise económica torna particularmente saliente a tensão entre a expansão dos mercados e a garantia de direitos de cidadania. É sobretudo por isso que o mais recente livro da filósofa norte-americana Debra Satz sobre os limites morais do mercado é tão oportuno. Em Why Some Things Should Not Be for Sale? The Moral Limits of Markets, Satz resume o seu trabalho das últimas duas décadas acerca da crescente mercadorização de bens e serviços. Posicionando-se nos debates filosóficos liberais e social-democratas, sobretudo anglo-saxónicos, sobre a natureza e lugar dos mercados, procura elencar razões que fundamentem a intuição amplamente partilhada de que há coisas que não devem ser colocadas à venda.

Tomando como ponto de partida a heterogeneidade dos mercados e a constatação de que há mercados que suscitam uma reação quase visceral de rejeição que os distingue de mercados mais convencionais, como os mercados de automóveis ou de maçãs, Satz investiga pormenorizadamente cinco transações apelidadas de potencialmente "tóxicas" - as barrigas de aluguer, a prostituição, o trabalho infantil, a servidão e a comercialização de órgãos humanos -, desenvolvendo argumentos que possam eventualmente justificar o seu bloqueio. Antes dos capítulos mais empíricos, o leitor pode contar com a construção de uma grelha analítica que recupera e sistematiza autores, na tradição de economia política clássica, que cedo reconheceram a existência de diversos tipos de mercados e os seus impactos nos valores que são nutridos e nas relações de liberdade e igualdade entre os membros da sociedade. Com efeito, como Satz assinala com enorme clareza e poder de síntese, esta tradição salientou que a estrutura de certos mercados - por exemplo, a maior ou menor facilidade de abandonar uma transação e de encontrar alternativas não-mercantis - determina se a relação social entre as partes vai ser marcada por uma maior ou menor liberdade ou subalternidade. Também notou que aquilo que uma pessoa pode fazer e ser, bem como os seus desejos e ambições, é fortemente influenciado pela posição que ocupa no mercado de trabalho. Expondo um Smith muito menos marcado por inclinações neoliberais, Satz sublinha, por exemplo, que Smith e Marx estavam conscientes de 
que a crescente divisão do trabalho estava a contribuir para a desqualificação e o empobrecimento mental de amplos segmentos das classes trabalhadoras.

De igual modo, Satz reconhece que os mercados são estruturas políticas, porque determinam o modo como os recursos são produzidos e distribuídos entre as várias classes sociais, bem como estruturas culturais, na medida em que as relações de produção e troca contêm sempre um potencial transformador do ser humano. Daqui decorre um distanciamento crítico face à economia convencional contemporânea, que, ao separar o mercado do seu contexto político e moral, reduziu esta instituição a um neutro mecanismo de afetação de recursos e a relações fetichistas entre coisas. A reintrodução de critérios ético-políticos tão amplos quanto necessários para a avaliação de mercados concretos exige, portanto, a superação desta forma arreigada de ver as coisas, que também fez o seu curso em certos ramos da filosofia social. As relações sociais subjacentes às transações mercantis constituem então o objeto de estudo desta obra. Aquelas determinam o modo como nos relacionamos uns com os outros e, em última análise, quem somos e em que tipo de sociedade vivemos. Para o efeito, Satz propõe uma grelha que procura avaliar as circunstâncias e a relação entre as partes, bem como as consequências da transação mercantil para os indivíduos envolvidos e para a sociedade em geral. Segundo a autora, há boas razões para impor limites aos mercados, banindo-os ou regulando-os estritamente, em quatro situações distintas, mas potencialmente interligadas. Em primeiro lugar, é importante considerar a vulnerabilidade das partes, ou seja, quando as pessoas são tão pobres ou estão de tal modo desesperadas, ou quando o seu poder negocial é de tal forma limitado, que são totalmente incapazes de influenciar os termos de uma transação. Em segundo lugar, temos os casos de "agência fraca", ou seja, quando as pessoas não têm capacidade para avaliar os termos da transação, quer porque não possuem informação necessária sobre os bens, ou porque não podem, com realismo, ser consideradas autónomas (é o caso das crianças). Em terceiro lugar, é importante considerar que certas transações mercantis geram sistematicamente resultados de tal forma nefastos para indivíduos em certas posições sociais que bloqueiam a sua capacidade para satisfazer certas necessidades e para participar como iguais em certas esferas da vida de uma comunidade política democrática. Finalmente, é importante não esquecer os resultados nocivos de certas transações mercantis para terceiros não diretamente envolvidos numa transação, ou para a sociedade no seu conjunto, nomeadamente os seus efeitos sobre formas de igualdade, de autonomia e de dignidade a que coletivamente se pode legitimamente aspirar. Esta última situação tem a vantagem de chamar a nossa atenção para os custos sociais de certas escolhas individuais de mercado, que podem limitar as escolhas disponíveis para terceiros. Por exemplo, a conivência com formas de trabalho infantil tem um impacto negativo sobre os salários dos adultos em muitos setores, o que compele muitas famílias a forçar as suas crianças a trabalhar para assegurar a subsistência, engrossando assim o número de escolhas trágicas. A inexistência de um salário mínimo, para dar mais um exemplo, ao admitir uma maior variedade de transações permissíveis na esfera laboral, coloca muitos trabalhadores numa situação vulnerável, o que potencia escolhas patronais medíocres, retirando incentivos para a modernização económica, afetando adversamente as escolhas sociais disponíveis no futuro.

A proposta de Satz é mais exigente do que aquilo que designa por propostas 
igualitárias "genéricas”, que se centram apenas nas condições de partida das partes envolvidas, nomeadamente na desigual distribuição de recursos, que compele as camadas mais destituídas da população a efetuar transações indesejáveis. Ao aceitar que à partida não existem limites para os mercados, desde que os recursos dos que neles transacionam possam ser redistribuídos para atingir determinadas soluções eficientes, esta variedade de igualitarismo tende, por exemplo, a ocultar efeitos indesejáveis sobre as normas sociais que organizam a vida em sociedade, o que pode constituir uma razão válida para a sua contestação e bloqueio. Embora também seja crítica do que se designa por "igualitarismo específico”, posição segundo a qual existem, em certas esferas de uma vida social plural, boas razões igualitárias, assentes nas representações sociais prevalecentes, para distribuir certos bens de acordo com critérios não-mercantis - votos, decisões judiciais, prémios, afetos, órgãos, saúde, etc. -, a verdade é que Satz está muito mais próxima das posições de autores como Michael Walzer ou Elizabeth Anderson do que admite. Tal acontece porque partilha a ênfase na existência de uma comunidade política democrática, cujos valores comuns se exprimem, entre outras, pelas formas como certos bens são provisionados de acordo com critérios não-mercantis, como a necessidade ou o merecimento. De resto, não se pense que Satz concebe os seus critérios de uma forma rígida. Para além da análise das transações mercantis particulares, há que analisar o impacto do bloqueio de mercados, por exemplo, se a proibição do mercado não dá origem ao surgimento de mercados subterrâneos com consequências ainda mais perniciosas sobre o indivíduo ou a sociedade. E aqui revela-se a sofisticação da grelha normativa proposta na sua aplicação aos estudos de caso.
Apenas no final do livro, Satz constata que, de um modo não intencional, os casos abordados dizem respeito a mercados que se relacionam com o corpo humano. Tal se deve ao facto, segundo a autora, de estes mercados tornarem mais saliente o modo como as transações mercantis influenciam as capacidades humanas e as relações políticas e sociais que os diversos mercados sustentam e apoiam, incluindo os seus efeitos sobre os ricos e pobres, mulheres e homens, mais e menos poderosos.

Embora a discussão possa sugerir que as questões de ordem moral e política estão confinadas a objetos que se distinguem das mercadorias convencionais, esta impressão não se confirma com uma leitura mais atenta. Apesar de o fazer de uma forma parcelar e algo dispersa ao longo do livro, Satz deixa clara a ideia de que os mercados, quaisquer que sejam, são construções políticas cujo funcionamento depende de um conjunto variado de outras instituições não-mercantis, como sejam o poder legislativo e judicial, e de valores e normas sociais, como a confiança e a reciprocidade. A relevância da análise moral dos mercados reside precisamente no conhecimento dos efeitos culturais e políticos sobre as instituições que os sustentam, e portanto sobre os valores e as relações sociais de que depende uma sociedade capitalista. No entanto, lamenta-se que Satz perca tão pouco tempo com mercados "tóxicos" com maior impacto sistémico, como os mercados de ativos financeiros também designados de "tóxicos", já que a sua grelha se prestaria à sua análise crítica em tempos de crise da financeirização. Num certo sentido, Satz cai na armadilha de devotar a sua atenção a mercados bastante discutidos nos fóruns académico e político, mas cuja prevalência e importância sistémica são relativamente diminutas.

O que ressalta da análise destes mercados particulares, que em boa verdade não são 
formalmente reconhecidos na generalidade dos países, é a importância da regulação apertada das relações laborais e a defesa do Estado-Providência para a preservação das sociedades democráticas. Nas sociedades capitalistas contemporâneas, a dignidade humana e a garantia de uma sociedade entre iguais só estão temporária e localmente garantidas por uma regulação vigorosa do mercado de trabalho, face à relação intrinsecamente desigual entre trabalhadores e empregadores, e pela provisão de bens fundamentais, a educação e a saúde, através de mecanismos não-mercantis. Por sinal, duas dimensões que têm sido particularmente erodidas pela financeirização e pelas suas crises. Com efeito, Satz torna muito claro que uma sociedade não é verdadeiramente democrática se as suas crianças não acederem a serviços de saúde e educação suficientes para que na idade adulta possam estar em condições de participar, em relações de igualdade, em processos de deliberação coletivos. Esta admissão tem, contudo, implicações muito mais radicais do que Satz está disposta a reconhecer. No atual contexto de crise, as regressivas alterações ao código laboral e a retração do Estado-Providência, em Portugal bem como em outros países europeus, fazem antever um retrocesso social com um agravamento das desigualdades de tal ordem que pode por em causa a própria democracia. Este livro dá-nos instrumentos analíticos para avaliar criticamente e contestar tais processos, bastando para isso colocar a ênfase em mercados mais relevantes e com impactos mais sistémicos.

\section{Ana Cordeiro Santos}

\section{Barreto, António; Benavente, Ana; Figueiredo, Eurico; Ferreira, J. M. e Alexandre, Valentim (2011), Pátria utópica: o Grupo de Genebra revisitado. Lisboa: Bizâncio, 360 pp.}

Em Pátria utópica, António Barreto, Ana Benavente, Eurico Figueiredo, José Medeiros Ferreira e Valentim Alexandre revisitam em conjunto a decisão do exílio, o seu engajamento político em clima universitário, a estadia em Genebra como espaço marginal de resistência, de formação pessoal e académica e, por fim, o seu regresso à Pátria. A referência às aspirações e lutas políticas, à prisão, e tortura nalguns casos, às discussões nos Cafés Landolt e $d u$ Commerce em Genebra, aos debates nos comícios europeus, às incertezas e certezas pessoais, às utopias e distopias faz parte da aventura comum, embora com trajetórias singulares, destes cinco protagonistas. Ao longo das cinco narrativas, torna-se claro que o exílio, encarado pela tradição literária do exílio (ver por exemplo as reflexões de importantes autores diaspóricos como E. Said, T. W Adorno, G. Agamben, H. Arendt, S. Hall, J. Joyce, C. Magris, A. Camus) como um "entre-lugar", um "lugar em trânsito", não representou para os autores nem um cárcere, nem uma mera passagem física, temporal e objetiva, mas foi, essencialmente, um locus de construção e reconstrução de um novo eu, potenciador de uma experiência interpessoal e intercultural que ultrapassou as barreiras instauradas e gerou espíritos cosmopolitas. Contudo, o paradoxo do exílio, o sentimento ambíguo que oscila entre a exclusão, a nostalgia, a ausência, a perda de raízes, por um lado, e os novos territórios de experiência, de liberdade e de esperança, por outro, modelou a experiência tão inextricavelmente unida ao devir político e social deste grupo de intelectuais 
Porém, para compreender as circunstâncias que contribuíram para o exílio do Grupo de Genebra, precisamos de retomar a primeira parte do livro intitulada "Em Portugal, abafava-se". A. Barreto assume que "[e]stava farto de censura [...] Sonhava com revoluções [...]", queria ler jornais feitos em liberdade e ver filmes sem censura (40). A. Benavente, a "adolescente revoltada e voluntariosa" que incorpora o papel da mulher, do feminino na contracultura, sonhava com a liberdade num "país que era fechado, autoritário e pobre, o regime era fascista e colonialista" (57). E. Figueiredo, envolto nas estórias de heroísmo e bravura familiar, envolveu-se no movimento estudantil e na luta política a partir de 24 de março de 1962. A partir desta data não pôde recuar. J. Medeiros Ferreira, o "representante orgânico da geração estudantil” (79), desempenhou funções determinantes nos círculos dirigentes e acabou preso pela PIDE. Com uma "Carta Aberta ao Povo Português" a explicar as razões da sua partida inicia uma nova etapa da sua luta e resistência política. Agora no exílio. V. Alexandre sentia-se não só na oposição ao regime salazarista, mas também do "lado de fora" por não ser católico. Contra a sua convicção política fora mobilizado para a Guiné, onde acabou por desertar "por imperativo de consciência" e em 1971 rumou para a Europa (117). Enquanto as manifestações contra a repressão política de regime autoritário germinavam pelas universidades e as perseguições aumentavam, os membros do Grupo de Genebra iam se despedindo da Pátria e chegando à Súça. $\mathrm{Na}$ fase do exílio, o grupo nunca vacila relativamente à sua missão intelectual e política. Este grupo, que falava a verdade ao poder (E. Said), interiorizou o compromisso do intelectual autónomo, liberto de quaisquer restrições. Neste caso, o capital militante no exterior serviu para informar a Europa sobre a repressão exercida em Portugal e desmistificar a imagem de Portugal na opinião pública. Esta ação de denúncia realizava-se não somente com boletins e panfletos, mas também com a participação em eventos universitários europeus.

Mas afinal o que significou o exílio para estes cinco intelectuais?

Para A. Barreto foi a descoberta de "ideias e cultura para além dos estereótipos realistas. Havia pensamento e liberdade para além dos catecismos. [...] Agora vivia em liberdade, ponto final" (127). O sociólogo refere a Universidade de Genebra como contributo maior para o seu crescimento; o cosmopolitismo de Genebra (143); a sua experiência como assistente (131) e como investigador nas Nações Unidas; a amizade com os coautores deste livro, que tiveram "talvez as mais interessantes discussões políticas sobre Portugal" (140); o abandono do Partido Comunista; a publicação da revista Polémica e o sentimento de desenraizamento, de estrangeirado, quando declara que "estrangeiro uma vez é estrangeiro para sempre” (141-142). Este desabafo está em perfeita sintonia com a declaração de Elie Wiesel (O Tempo dos Desenraizados [2003]. Lisboa: Dom Quixote, 18) quando assume que "[o] antigo refugiado permanece refugiado para o resto da vida”. Ora, esta sensação de não-pertença foi intensamente vivida por A. Benavente. Escreve que, no início, sentia-se de passagem, num lugar de empréstimo. Era uma estrangeira à procura de liberdade, de vida, de um caminho que um dia lhe permitisse regressar (149). Para além de jovem, era mulher, e estes dois aspetos faziam com que fosse muitas vezes levada pouco a sério. Mas a irrupção do maio de 68 deu a ela e a todas a mulheres segurança, ousadia e libertação plena. Enquanto lia o Homem Unidimensional de Marcuse militava contra a injustiça, contra a opressão, pela liberdade, pela democracia, pela igualdade. Integrava-se 
igualmente na revista Polémica e desenvolvia a sua formação académica. E. Figueiredo aponta no seu testemunho duas fases distintas na Suíça: o pesadelo em Lausana e os melhores tempos da sua vida em Genebra. Em Genebra pôs o acento tónico na sua vida profissional e fez doutoramento em Medicina pela Universidade de Genebra (187). Contribuiu ativamente na revista Polémica e encara os seus anos no exílio como os mais saudosos da sua vida (188). J. Medeiros Ferreira, "o grande animador da boa disposição" do grupo, ao chegar a Genebra requereu imediatamente o estatuto de refugiado político e matriculou-se na Faculté des Sciences Économiques et Sociales, onde se tornou mais tarde assistente. Participou com A. Barreto e C.Almeida em Encontros sobre a Esquerda na Europa, foi a comícios em Londres e Manchester com Amílcar Cabral e em 1973 concebeu a tese da política dos três D (descolonizar, democratizar, desenvolver), que enviou para o Congresso em Aveiro. Embora exilado, conseguiu participar no censurado espaço público português e a sua tese acabou por ter alguma influência nos acontecimentos. Tal como os outros coautores, os seis anos de exílio acabaram por ser os melhores da sua vida. Finalmente, V. Alexandre, o último a chegar à Suíça. Pediu equivalência à licenciatura em Direito com vista a um doutoramento. No exílio, deu continuidade à sua formação académica, mas a sua relação com a Suíça foi sempre, assevera, "a de um espectador interessado".

O exílio termina a 25 de abril de 1974, e o Grupo de Genebra está determinado a regressar à Pátria. O regresso foi para todos, independentemente do percurso profissional, político e académico, um misto de emoções e contradições, de alegrias e tristezas, de sentimento de pertença e de perda, de esperança, liberdade extrema e desilusão. A gratidão e o elogio à cidade que os acolheu, Genebra, são constantes nos cinco trilhos de memória. Relembram a organização, os cafés, a universidade, o cosmopolitismo que pairava pela cidade. Enfim, uma experiência mágica, agora quase onírica, no imaginário deste grupo de intelectuais que nela construíram a sua vida "entre parênteses". Genebra deu-lhes capital cultural e um espaço livre onde puderam lutar pela liberdade de uma Pátria que permanece, todavia, utópica.

"A despedida da Europa" (142), como A. Barreto adverte, foi difícil, mas a edificação de uma sociedade livre e pluralista em Portugal e o sentido de cidadania cativou estes intelectuais comprometidos. O novo ciclo, o ciclo da construção de uma Pátria perfeita, manteve-se todavia inacabado. Embora tenha havido uma melhoria significativa a nível das liberdades, das condições de vida, da abertura do país, os autores finalizam o seu testemunho com alguma desilusão face ao país por que tanto lutaram: A. Barreto não se habitua a viver com muitas desigualdades ou entre muito pobres (224); A. Benavente critica a perda de sentido crítico num país que necessita de democratizar a sua democracia (250); E. Figueiredo revolta-se com a continuação de compadrio em 'liberdade' (261); J. M. Ferreira busca a autonomia dos "narcisismos concentrados" e permanece na busca de uma sociedade mais livre e igualitária; e V. Alexandre afirma, com desgosto, o desaparecimento das ilusões sobre experiências socialistas.

No Portugal do século XXI, nesta era incerta e inconstante, de crise económica, mas também social e política, na era onde os imperativos tecno-económicos colonizam as esferas do mundo da vida, onde o défice democrático é cada vez maior, torna-se crucial reavaliar a influência dos intelectuais em movimentos que sustentam a liberdade e dignidade humana. Isto significa que o intelectual tem de se desprender, utilizando as palavras de T. Adorno, 
do kitsch oficial, mas também não pode preconizar o papel de mero "intérprete cultural”, como Z. Bauman afirma. Ora, considerando a cultura do discurso crítico e o compromisso com a transparência, com os valores cosmopolitas, com as liberdades humanas, o intelectual irá certamente estimular debates que irão animar a civitas e proporcionar uma esfera pública incubadora de uma democracia deliberativa.
Desta forma, esperamos que o Grupo de Genebra, este Grupo de intelectuais autónomos, com sua vocação individual, energia, força e persistência, continue a propor à nossa Pátria - agora esvaziada de sentido crítico e esperança - novas utopias.

\section{Pilar Damião de Medeiros}

Livro apresentado pela autora a 16.03 .12 na Livraria Solmar, Ponta Delgada

\section{Ronald Chilcote (2010), The Portuguese Revolution: State and Class in the Transition to Democracy. Lanham, Maryland: Rowman \& Littlefield Publishers, $328 \mathrm{pp}$.}

Nos últimos anos, salvo o Centro de Documentação 25 de Abril da Universidade de Coimbra, um silêncio caiu sobre a academia portuguesa em relação aos acontecimentos de $1974 \mathrm{e}$ aos dois anos de intensas lutas políticas que abalaram Portugal. Uma narrativa consensual gradualmente fincou raízes, retratando abril como um desvio errático movido por um ingênuo e aventureiro grupo de oficiais, um avassalador evento psicológico, porém insignificante para o reordenamento sociopolítico. Esse silêncio, todavia, se rompe neste livro, fruto de três décadas de árdua e bem fundamentada documentação e pesquisa de campo, demandando um reexame de abril à luz dos conflitos de classe, dos rumos do capitalismo e do dilema da esquerda no poder político. $\mathrm{O}$ autor recorre à análise de classe em sua forma concreta, seguindo Marx, Gramsci e Poulantzas. Na conclusão, mostra como o abril de 1974 estabeleceu não apenas uma nova agenda teórica como também uma prática política centrada na democracia participativa.

O livro se divide em duas partes. Na primeira, composta pelos quatro capítulos iniciais, contextualiza as especificidades históricas do capitalismo português, as classes dominantes, a base material dos cinco regimes políticos, a legitimidade do Estado Novo e as causas da revolução. A segunda, formada pelos cinco capítulos seguintes, analisa os acontecimentos de abril, os dois anos de lutas políticas, a derrota da esquerda e a retomada da hegemonia burguesa. Nesse percurso Chilcote apresenta a diversidade de atores, forças políticas, partidos e movimentos sociais; os motivos da fragmentação interna do bloco do poder e o distanciamento do comando revolucionário da sua base de sustentação popular. Especificamente no nono capítulo, revela o verdadeiro significado político do "verão quente". Derrotadas as forças da esquerda, inicia-se uma revolução passiva, prolongando-se por duas décadas e anunciando a retomada da democracia pluralista sob a hegemonia da nova burguesia associada ao capital internacional. O primeiro capítulo resenha as diversas interpretações das origens do capitalismo português prevalecentes no meio acadêmico português. A pioneira interpretação de Villaverde Cabral relaciona a dependência sobre as riquezas coloniais ao bloqueio do capitalismo industrial. A agricultura permaneceu dominada por relações pré-capitalistas, a burguesia se limitou ao pequeno comércio urbano e o mercado 
interno estagnou quando a massa camponesa, expelida da terra, migrou, reduzindo o ritmo de crescimento populacional. Enquanto Cabral atribuía a estagnação do capitalismo moderno industrial à abundância da riqueza colonial, outra interpretação neo-smithiana inverte o argumento a favor da escassez de capitais. Para Halpern Pereira, a dependência de Inglaterra se estruturou em trocas desiguais, estagnando a indústria e transformando Portugal, em decorrência do século XIX, do terceiro mais rico para o mais pobre país europeu. Chilcote conclui com o argumento de que a frágil burguesia se submeteu constantemente ao Estado nos últimos quatro séculos, da monarquia ao capitalismo globalizado. O segundo e o terceiro capítulos se dedicam à economia política dos cinco regimes: monarquia e república (mercantilismo), fascismo corporativo (comercial, financeiro e industrial numa conjugação com as empresas estatais), autoritário progressista (capitalismo nacional formado com a nacionalização dos bancos) e democrático burguês (neoliberal e associado ao capital internacional). Especificamente o terceiro foca a ligação da base econômica com o poder político durante o Estado Novo, dividido em duas fases: 1926-1946 e 1946-1974. Na primeira, um decreto estatal estabeleceu a monopolização formal dos grupos empresariais, transformando-se, no segundo período, em conglomerados econômicos verticalizados, unificando investimentos industriais, comerciais e financeiros. Para Chilcote, a hegemonia burguesa se revelava, de um lado, pela sua crescente complexificação e integração e, de outro, pela desordem das empresas estatais. A adesão de Portugal à EFTA (European Free Trade Association), em 1959, distanciou mais ainda a burguesia do Estado Novo ao aproximar as empresas locais das multinacionais, enraizando o mercado interno na economia continental.
O quarto capítulo descreve as diversas interpretações da erosão da sustentação de classe do regime. Para Schmitter, o "desenvolvimento sem mudanças" perpetuou uma crônica instabilidade econômica, levando à centralização, repressão e eventualmente à deslegitimação do regime. A guerra colonial agravou mais ainda as fissuras, aflorando a oposição no exército. Enquanto para Boaventura de Sousa Santos a ruína do Estado Novo resultou de uma prolongada crise de legitimidade, seguida do colapso da hegemonia. A deslegitimação política seria fruto da incapacidade do regime para incluir novas classes sociais urbano-industriais nos aparelhos do Estado. A crise de hegemonia levou à cisão do bloco de sustentação de classe do regime entre a burguesia agrária, beneficiada pela exploração colonial, e a europeizada burguesia industrial.

A segunda parte, composta por quatro capítulos, relata uma previsível sequência de contradições inerentes aos momentos revolucionários. $\mathrm{O}$ processo começa com a composição inicial do MFA (Movimento das Forças Armadas), reunindo uma diversidade ideológica tanto da esquerda como da direita. A luta pelo poder entre militares progressistas e conservadores militariza o movimento, centraliza o poder e marginaliza os partidos políticos. Apesar do avanço da esquerda do MFA, o movimento se distancia de suas bases populares representadas pelos movimentos de bairro e sindicatos rurais e urbanos. No ápice do seu poderio político-institucional, veio a fragmentação interna das forças revolucionárias. O MFA se degenera numa personalização política, desencantando as forças populares, o verdadeiro sujeito da mudança social.

Este processo mostra como o dilema maior desta conjuntura foi percebido por Poulantzas, já em 1975. A luta em Portugal não poderia ser pelo socialismo, dados os 
limites objetivos de um país pequeno e isolado, mas pela hegemonia política no processo da democratização. Uma democracia participativa sustentada pelas forças populares seria o verdadeiro regime político da transição socialista, enquanto a centralização autoritária, mesmo sob o comando da esquerda, nada mais seria do que a preparação da retomada do domínio burguês. Essa observação inspirou Boaventura de Sousa Santos a declarar que o mesmo processo que suspendia e neutralizava o poder burguês simultaneamente impedia o poder popular. Quando veio a reação, em novembro de 1975 , o destino da isolada esquerda já estava selado. A burguesia, pelas mãos do PS, temeroso diante da premência de mais um ciclo de ditaduras, retoma a sua hegemonia. Amplia seu comando quando, em nome da estabilidade política e da continuidade democrática, mergulha na integração europeia, promovendo a sua fusão com o capital europeu.

$\mathrm{Na}$ conclusão o autor insiste que os erráticos eventos da revolução portuguesa deixaram mais do que imagens heroicas, redesenhando a teoria do poder e a prática política da nova esquerda. O discursivo e ambíguo programa socialista cede lugar à prática política centrada numa ligação umbilical entre as massas populares e a liderança política alimentada por uma democracia participativa. Em última instância, representa a luta pela hegemonia no processo de democratização que determina o destino dos sistemas políticos e dos rumos da economia. Chilcote mostra que quem governa, como governa e com que forças sociais se sustenta, sim, influencia e molda o futuro de sociedades.

Esse livro é imprescindível para compreender uma das conjunturas políticas mais marcantes da Europa contemporânea. Reunindo uma vasta bibliografia, oferece ao leitor um raro olhar sobre os sucessos e contradições das mudanças sociais. Uma tradução desta obra para português representaria uma importante adição para um intenso, porém esquecido, debate sobre abril em Portugal.

Jawdat Abu-El-Haj 